\title{
An ovarian steroid cell tumor with virilization and hypothyroidism: a case report
}

\author{
Chi-Feng Su • Po-Hui Wang • Shu-Chen Chen • \\ Joy Liao $\cdot$ Horng-Jyh Tsai
}

Received: 3 April 2007 / Accepted: 26 May 2007 /Published online: 23 June 2007

(C) Springer-Verlag 2007

\begin{abstract}
Steroid cell tumors are rare ovarian sex-cord stromal tumors with malignant potential. The majority of these tumors produce steroids with testosterone being the most common. The diagnosis of these rare tumors can be problematic especially in the case of a small nonpalpable ovarian tumor. A 41-year-old woman presented with the gradual onset of defeminization, mild hypothyroidism, and virilization. A physical examination revealed a relatively healthy woman with borderline hirsutism, clitoromegaly and adnexal fullness without a palpable tumor. Elevated serum levels of TSH and testosterone were found preoperatively. Five weeks after an oophorectomy, serum levels of TSH and testosterone returned to normal and menstruation returned. Nonpalpable virilizing ovarian steroid cell tumors may be difficult to diagnose. A careful study of the patient's history, the development of defeminization followed by virilization, and a "characteristic" ultrasonogram, can be helpful for diagnosis. Hormonal studies including thyroid function should also be considered in an ovarian steroid cell tumor.
\end{abstract}

Keywords Steroid cell tumor · Virilization · Virilizing ovarian tumor · Hypothyroidism · Elevated serum TSH

C.-F. Su • P.-H. Wang $\cdot$ H.-J. Tsai $(\bowtie)$

Department of Obstetrics and Gynecology,

Chung-Shan Medical University and Hospital,

110, Section 1, Chien-Kuo North Road,

Taichung 402, Taiwan

e-mail: cshy076@csh.org.tw

S.-C. Chen

Institute of Medicine,

Chung-Shan Medical University and Hospital,

Taichung, Taiwan

J. Liao

Dr. Joy's OBG Clinic,

Taichung, Taiwan

\section{Introduction}

Steroid cell tumors are rare ovarian sex-cord stromal tumors. Sex-cord stromal tumors account for $5 \%$ of all ovarian tumors, and steroid cell tumors account for less than $0.1 \%$ of all ovarian tumors [1]. The majority of these tumors produce hormones with testosterone being the most common. The diagnosis of these rare tumors can be problematic especially in the case of a nonpalpable ovarian tumor. This report describes the case of an adult woman presenting with the gradual onset of defeminization, mild hypothyroidism, virilization, and a small nonpalpable pelvic mass that proved to be a benign steroid cell tumor, not otherwise specified (NOS).

\section{Case report}

A 41-year-old female, G3P3, presented with a 5-year history of gradual defeminization including oligomenorrhea, nonspecific symptoms of hypothyroidism such as weight gain, and relatively slow motion. Amenorrhea and then the gradual onset of virilization followed including increased truncal hair and deepening of voice 2 years prior to this presentation. There was no acne or baldness. She was not taking any kinds of medication. She gained $10 \mathrm{~kg}$ of body weight over the previous 2 years. Her past medical history was significant for mitral valve prolapse with no limitation of physical activity. She was $167 \mathrm{~cm}$ in height and $88 \mathrm{~kg}$ in weight, with mild hirsutism of grade 1 . The thyroid gland was normal by palpation. A pelvic examination revealed a mildly enlarged clitoris, $10 \mathrm{~mm}$ in width, and right adnexal fullness without a palpable mass. The pubic hair development was at Tanner stage 4 .

Laboratory analyses showed normal blood counts and normal serum values of CA-125, prolactin, FSH, LH, and 
ACTH. The serum TSH level was $9.3 \mathrm{IU} / \mathrm{ml}$ (reference value, $0.25-4.0 \mathrm{IU} / \mathrm{ml}$ ), and the total testosterone level was $2.4 \mathrm{ng} / \mathrm{ml}$ (reference value, $0.06-0.86 \mathrm{ng} / \mathrm{ml}$ ). A transvaginal ultrasound identified a well-circumscribed, lobulated, solid, right ovarian tumor, $4.0 \times 3.2 \mathrm{~cm}$ in diameter (Fig. 1). The morphologic index of this tumor was 2 (the volume 0 , the structure 2) [2]. Tumor vessels presented with a 0.59 flow pulsatility index, and a 0.43 resistance index in the Doppler study. No ascites or other abnormalities were present. The patient underwent an exploratory laparotomy with a right oophorectomy. The ovarian venous blood was not sampled during the operation. The left ovary and the uterus were normal.

A gross pathological examination of the ovary revealed a yellow-orange solid mass, $5.6 \times 3.7 \times 3.0 \mathrm{~cm}$ in diameter (formalin-fixed section is shown in Fig. 2). Microscopically, the sections were consistent with a benign ovarian steroid cell tumor, NOS (Fig. 3). There were no luteinized stromal cells or luteinized theca cells present. Five weeks after the operation, serum levels of TSH and testosterone returned to normal, and the first postoperative menstrual flow was normal. The patient also lost $1.5 \mathrm{~kg}$ of body weight without any effort. She was in euthyroid condition and disease-free 1 year after surgery at the time of the report.

\section{Discussion}

Scully initiated the term "steroid cell tumor of the ovary" in 1979. These tumors were previously classified as lipid or lipoid cell tumors. Lipoid cell tumors are believed to arise in adrenal cortical rests that reside in the vicinity of the ovary. More than 100 cases have been reported, and bilateral disease has been noted in only a few. The early nomenclatures were misleading because some tumors have little or no lipid present. The term "steroid cell tumor" more accurately

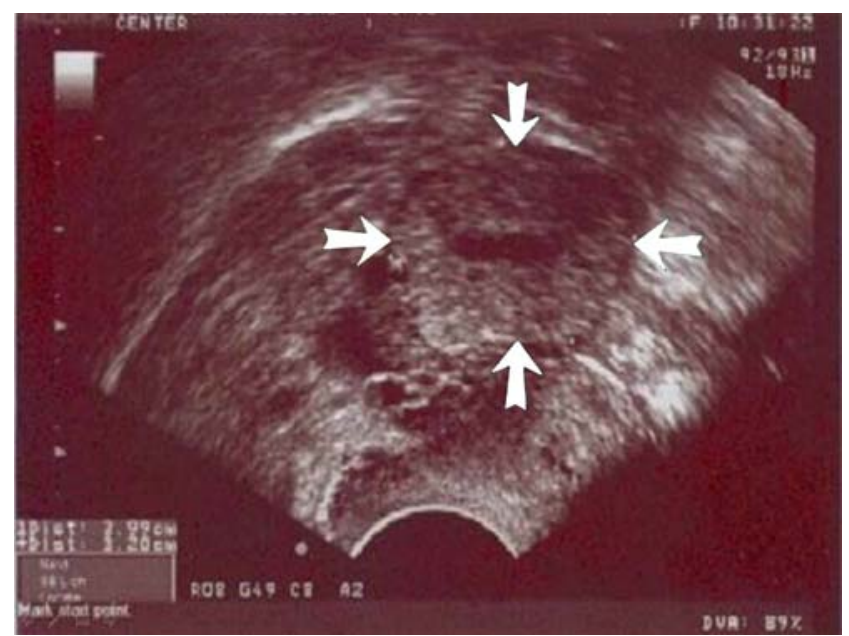

Fig. 1 Transvaginal ultrasound image of steroid cell tumor identifying a well-circumscribed, lobulated, solid, right ovarian tumor (arrows), $4.0 \times 3.2 \mathrm{~cm}$ in diameter

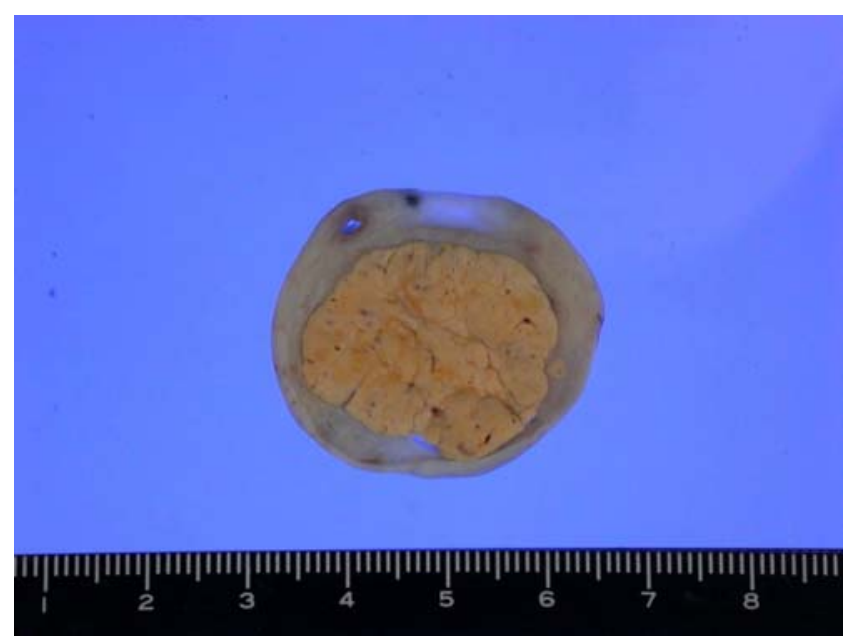

Fig. 2 Gross appearance of steroid cell tumor, NOS. A formalin-fixed section of right ovary showing a yellow-orange solid, well-demarcated, typical tumor $4.5 \times 3.7 \mathrm{~cm}$ in diameter

describes the morphological appearance of these tumors and provides insight into their clinical manifestations. There are three steroid cell tumor subtypes: steroid cell tumor (NOS), stromal luteoma, and Leydig cell tumor [1, 3]. In 1987, Hayes and Scully reported the largest series of patients $(n=63)$ with steroid cell tumor, NOS [1]. The tumors were typically solid and well circumscribed, occasionally lobulated, and rarely bilateral. They usually occurred in adults, with an average age at diagnosis of 43 years. The tumors were composed of two similar-appearing polygonal cell types that differed only in their cytoplasmic appearance (eosinophilic versus vacuolated). The most common initial manifestation was virilization (41\%). In 24 cases $(38 \%)$, the tumor was designated as probably benign (no evidence of spread beyond the ovary 3 or more years postoperatively) [1].

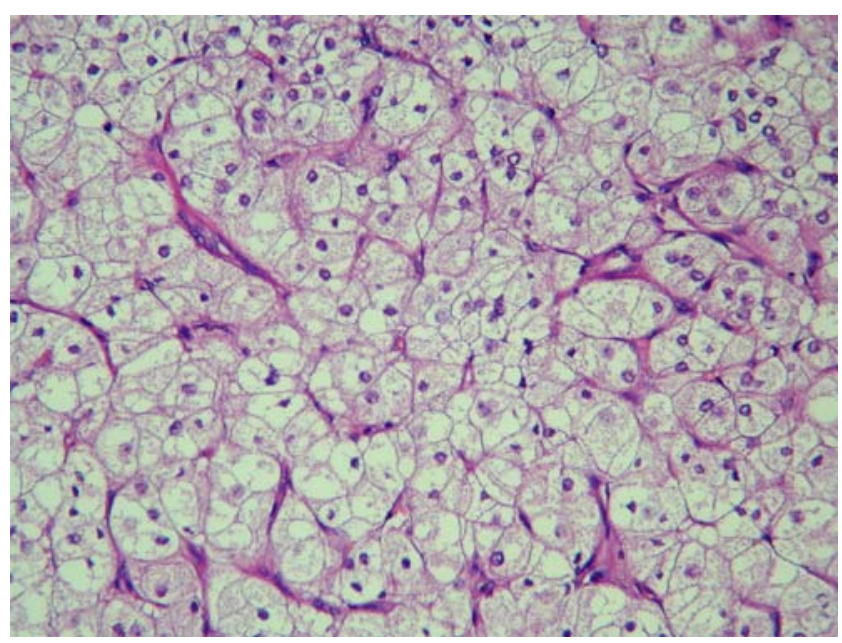

Fig. 3 Microscopic appearance of steroid cell tumors showing large arrogates of typical polygonal-to-round tumor cells having distinct cell borders, central nuclei, prominent nucleoli and moderate-to-abundant spongy or eosinophilic granular cytoplasm, intersected by delicate fibrous bands. (H\&E, 400×) 
Steroid cell tumors, NOS, sometimes produce hormones other than testosterone, for example, estradiol secretion has been reported in $6-23 \%$ of patients. These tumors have been associated with Cushing's syndrome in $6-10 \%$ of cases [1]. They may secrete other hormones such as androstenedione, dehydroepiandrosterone sulfate (DHEA-S), estrogens, 17hydroxyprogesterone, ACTH, and there are even reports of the secretion of cortisol, rennin, and so on. We do not have direct evidence that the tumor in our patient secreted TSH and testosterone, but the elevated serum levels of TSH and testosterone returned normal after surgery. In general, the degree of TSH elevation correlates with the clinical severity. The serum TSH level of this patient was mildly elevated; therefore we encountered only a few nonspecific symptoms of hypothyroidism.

In a MEDLINE and a PubMed literature search from 1966 to March 2007 using search terms "ovarian neoplasm, ovarian sex cord-stromal tumors, ovarian steroid cell tumor, lipoid cell tumor, or lipid cell tumor" and "virilization or hypothyroidism," we were unable to find any cases of ovarian steroid cell tumor and hypothyroidism. About 6 months prior to seeing this patient, however, we encountered and then reported a patient with hypothyroidism and hyperlipidemia, associated with a virilizing ovarian steroid cell tumor. That patient had a 15 -year history of hypothyroidism under fair control with thyroxine and an 8-year history of hyperlipidemia presenting with abrupt onset of oligomenorrhea, progressive virilization with elevated testosterone level, and a nonpalpable benign steroid cell tumor [4]. These two patients are the only two steroid cell tumors at this hospital, and both cases were associated with hypothyroidism. We raise the question of whether thyroid function should also be evaluated for this tumor.

The diagnosis of these rare tumors can be problematic, especially in the case of a nonpalpable ovarian tumor. A careful study of the patient's history can eliminate medications as a cause of virilization and hirsutism. Our patient did not take any medicines. Development of defeminization followed by virilization can be a helpful sign for diagnosis. Preoperative evaluation for women with virilization includes a bimanual examination, serum testosterone, DHEA-S, and computerized tomography (CT) of the adrenals and ovaries [5]. Although a CT can identify an adrenal mass as small as $1.5 \mathrm{~cm}$, transabdominal and transvaginal ultrasounds are very useful in evaluating ovarian tumor size and morphology [6]. Therefore, a gray-scale transvaginal sonography combined with color Doppler studies can make the diagnosis of small steroid cell tumors easier, and at times, better than more costly imaging modalities [7]. In this study, we followed this suggestion and demonstrated the "characteristic" ultrasonogram of this small tumor that was very useful in the preoperative assessment.

It has been suggested that ovarian and adrenal venous catheterization and sampling not be performed routinely in women presenting with symptoms and signs of hyperandrogenism; venous catheterization and sampling should be reserved for patients in whom uncertainty remains [8]. We omitted ovarian vein blood sampling, since ovarian tumor had been diagnosed with transvaginal sonography preoperatively. When in doubt, exploratory laparotomy with intraoperative selective blood sampling of the ovarian veins might be a useful approach in patients without accurate preoperative localization of androgen-producing tumors of the ovaries [9].

The differential diagnosis of steroid cell tumors would include other sex cord-stromal tumors, primary or secondary carcinomas, and melanomas. In young women with virilization or in young adults, steroid cell tumors in other locations should be sought $[10,11]$. Although the tumor with virilization and rarely associated massive ascites might look malignant clinically, the tumor might prove to be benign [12]. In young adult women with secondary amenorrhea, or in perimenopausal women with severe hyperandrogenism and virilization, Leydig cell tumor of the ovary should be considered [13, 14]. Of the different markers that have been reported to stain ovarian stromal tumors, inhibin has proven to be the most helpful; immunostaining with calretinin has also being suggested as a sensitive marker $[15,16]$.

The management of steroid cell tumors, NOS, is similar to other ovarian stromal tumors, i.e., surgery, ranging from conservative surgery to complete surgical staging. Postoperative follow-up should include monitoring of hormone levels. Therapy should be individualized based on tumor histology, surgical staging, and the desire for future childbearing. Our patient was apparently healthy at 1-year follow-up examination and enjoyed her life.

\section{References}

1. Hayes MC, Scully RE (1987) Ovarian steroid cell tumor (not otherwise specified): a clinicopathological analysis of 63 cases. Am J Surg Pathol 11:835-845

2. Ueland FR, DePriest PD, Pavlik EJ et al (2003) Preoperative differentiation of malignant from benign ovarian tumors: the efficacy of morphology indexing and Doppler flow sonography. Gynecol Oncol 91:46-50

3. Scully RE, Young RH, Clement PB (1998) Tumors of the ovary, maldeveloped gonads, fallopian tube, and broad ligament. Armed Forces Institute of Pathology, Washington DC, pp 227-238

4. Tsai HJ, Chen SC, Wei HY, Chen GD (2007) Hypothyroidism and hyperlipidemia with a virilizing ovarian steroid cell tumor, not otherwise specified. Gynecol Endocrinol 23:69-71

5. Surrey ES, de Ziegler D, Gambone JC et al (1988) Preoperative localization of androgen-secreting tumors: clinical, endocrinologic, and radiologic evaluation of ten patients. Am J Obstet Gynecol 158:1313-1322

6. Outwater EK, Marchetto B, Wagner BJ (2000) Virilizing tumor of the ovary: imaging features. Ultrasound Obstet Gynecol 15:365-371 
7. Monteagudo A, Heller D, Husami N et al (1997) Ovarian steroid cell tumors: sonographic characteristics. Ultrasound Obstet Gynecol 10:282-288

8. Kaltsas GA, Mukherjee JJ, Kola B et al (2003) Is ovarian and adrenal venous catheterization and sampling helpful in the investigation of hyperandrogenic women? Clin Endocrinol 59:34-43

9. Bohlmann MK, Rabe T, Sinn HP, Strowitzki T, von Wolff M (2005) Intraoperative venous blood sampling to localize a small androgenproducing ovarian tumor. Gynecol Endocrinol 21:138-141

10. Smith D, Crotty TB, Murphy JF, Crfton ME, Franks S, McKenna TJ (2006) A steroid cell tumor outside the ovary is a rare cause of virilization. Fertil Steril 85:227

11. Liu AX, Sun J, Shao WQ, Jin HM, Song WQ (2005) Steroid cell tumors, not otherwise specified (NOS), in an accessory ovary: a case report and literature review. Gynecol Oncol 97:260-262
12. Kim YT, Kim SW, Yoon BS et al (2007) An ovarian steroid cell tumor causing virilization and massive ascites. Yonsei Med J 48:142-146

13. Elbadrawy M, Davies N (2005) Secondary amenorrhea due to Leydig cell tumour. J Obstet Gynaecol 25:529-530

14. Nardo LG, Ray DW, Laing I, William C, McVey RJ, Seif MW (2005) Ovarian Leydig cell tumor in a peri-menopausal woman with severe hyperandrogenism and virilization. Gynecol Endocrinol 21:238-241

15. Mohanty A, Trujillo YP (2006) Virilization and left adnexal mass in a 35-year-old woman. Arch Pathol Lab Med 130:113-114

16. Deavers MT, Malpica A, Ordonnez NG, Silva HG (2003) Ovarian steroid cell tumors: an immunohistochemical study including a comparison of calretinin with inhibin. Int $\mathrm{J}$ Gynecol Pathol $22: 162-167$ 